\title{
A Quality Function Deployment-Based Model for Cutting Fluid Selection
}

\author{
Kanika Prasad and Shankar Chakraborty \\ Department of Production Engineering, Jadavpur University, Kolkata 700 032, India \\ Correspondence should be addressed to Shankar Chakraborty; s_chakraborty00@yahoo.co.in
}

Received 16 November 2015; Accepted 24 December 2015

Academic Editor: Huseyin Çimenoğlu

Copyright @ 2016 K. Prasad and S. Chakraborty. This is an open access article distributed under the Creative Commons Attribution License, which permits unrestricted use, distribution, and reproduction in any medium, provided the original work is properly cited.

\begin{abstract}
Cutting fluid is applied for numerous reasons while machining a workpiece, like increasing tool life, minimizing workpiece thermal deformation, enhancing surface finish, flushing away chips from cutting surface, and so on. Hence, choosing a proper cutting fluid for a specific machining application becomes important for enhanced efficiency and effectiveness of a manufacturing process. Cutting fluid selection is a complex procedure as the decision depends on many complicated interactions, including work material's machinability, rigorousness of operation, cutting tool material, metallurgical, chemical, and human compatibility, reliability and stability of fluid, and cost. In this paper, a decision making model is developed based on quality function deployment technique with a view to respond to the complex character of cutting fluid selection problem and facilitate judicious selection of cutting fluid from a comprehensive list of available alternatives. In the first example, HD-CUTSOL is recognized as the most suitable cutting fluid for drilling holes in titanium alloy with tungsten carbide tool and in the second example, for performing honing operation on stainless steel alloy with cubic boron nitride tool, CF5 emerges out as the best honing fluid. Implementation of this model would result in cost reduction through decreased manpower requirement, enhanced workforce efficiency, and efficient information exploitation.
\end{abstract}

\section{Introduction}

There exists an assortment of machining operations for fabrication of finished metal parts/products for various applications across diverse categories of manufacturing industries. An enormous amount of heat is generated during those machining operations due to plastic deformation of the chips produced, friction between the cutting tool and chips, and interaction between the cutting tool and workpiece. The rise in temperature as a result of the generated heat affects both the cutting tool and the workpiece, which in turn leads to several predicaments, like (a) difficulty in handling and controlling dimensional requirements of the workpiece, (b) reduction in hardness of the cutting tool, and (c) formation of built-up edge on the rake face of cutting tool, thereby modifying the geometry of the cutting tool and affecting surface finish of the workpiece. Moreover, it is expected that the machine tools employed for performing the cutting operations should run efficiently, productively, and reliably for substantial period of time. Therefore, cutting fluids are extensively utilized in manufacturing industries to lessen the effect of generated heat on the final product and to avert the abrupt breakdown of machine tools. They have a strong impact on the cutting tool's life, quality of the finished part/ product, and productivity and efficiency of the machining process, when considered as a whole. Thus, cutting fluids play a major role in machining operations.

At earlier days, a machine tool was polished and cooled through application of plain oils, also termed as cutting fluid, on it. Gradually, formation of cutting fluids has become more and more complex with dynamic business environment, global competition, continuously improving technology, and advent of more intricate metal removal processes. At present, they comprise special blends/mixtures of chemical additives, lubricants, and water-based oils to meet the performance and productivity demands of different manufacturing processes. In addition, each cutting fluid has a disparate composition to cater varying convoluted requirements of the machining operation. For example, depending on the machining speeds and loads, different base oil viscosities for cutting fluids are needed. Similarly, dissimilar thickeners provide distinct characteristics, like good adhesion to workpiece surface or good 
corrosion resistance. There is a wide range of cutting fluids available in the market, each having unique composition and property, and, therefore, recognizing a particular cutting fluid as the most suitable choice from those present alternatives is an arduous task. In a workshop, assorted machining operations are carried out on various workpiece materials and, thus, it is not at all economical to store a large variety of cutting fluids to meet all those machining requirements. Besides, the functional and economical requirements and compatibility of the cutting fluids with other components of the machine tool should be contemplated while choosing the best alternative. Compatibility issue arises because interaction of the cutting fluid is not limited to cutting tool only but also with other tool parts, like seal, paint of the machine tool, and so forth. Additionally, it is acknowledged that a cutting fluid which is otherwise appropriate may not be preferred by the end user owing to its odour or viscosity. Moreover, there may be instances, where multiple machining operations are conducted employing the same machine tool. These factors further complicate the nature of the selection problem. Thus, this paper proposes the development of a decision making model which aids in selecting a suitable cutting fluid for a given machining condition using quality function deployment (QFD) technique in a cost effective manner. A user friendly software prototype in Visual BASIC 6.0 is designed to ease out the entire cutting fluid selection procedure.

\section{Literature Review}

De Chiffre and Belluco [1] compared different methods for cutting fluid performance evaluation involving metal cutting operations under controlled laboratory conditions. Ávila and Abrão [2] analyzed the performance of three types of cutting fluids in dry cutting operation for continuously turning hardened AISI 4340 steel using mixed alumina inserts. Axinte et al. [3] proposed a novel approach to examine the cutting fluid efficiency in turning operation. Rao and Gandhi [4] developed a methodology to select the most appropriate cutting fluid for a given machining application using digraph and matrix approach. Sales et al. [5] discussed about the comparative advantages and disadvantages of using cutting fluids as well as dry cutting operation. Soković and Mijanović [6] analyzed the ecological parameters of cutting fluids and their influence on machinability characteristics of work materials. Sun et al. [7] developed a two-grade fuzzy synthetic decision making system employing analytic hierarchy process (AHP) for evaluating performance of grinding fluids. De Chiffre and Belluco [8] presented an analysis of cutting fluid performance in different metal cutting operations. Tan et al. [9] developed a multiobjective decision making model of cutting fluid selection for green manufacturing. Varadarajan et al. [10] compared hard turning operation with minimal fluid application in its optimal mode with conventional wet and dry turning operations under identical cutting conditions. Cakir et al. [11] evaluated different cutting fluid applications in various machining processes. Rao et al. [12] studied the role of emulsifier on the properties and performance of a cutting fluid. Jayal and Balaji [13] studied the effects of different cutting fluid application methods on tool wear during machining of AISI 1045 steel using flat-faced and grooved, coated carbide cutting tools. Rao and Patel [14] applied preference ranking organization method for enrichment evaluations (PROMETHEE) for cutting fluid selection while considering both crisp and fuzzy criteria. Fratila and Caizar [15] presented a case study on the optimization of face milling parameters considering the cooling lubrication technique as an influencing factor on surface quality. Meciarova and Stanovsky [16] developed a computer software for optimization of the cutting fluid selection procedure with respect to human and environmental hazards. Abhang and Hameedullah [17] combined technique for order preference by similarity to ideal solution (TOPSIS) and AHP methods to select a suitable lubricant from a number of available alternatives for machining of EN-31 steel workpiece with tungsten carbide inserts. Jagadish and Ray [18] developed a methodology for selection of the optimal cutting fluid for reduced machining cost, while minimizing the environmental impact and maximizing the quality based on sustainable design. Deshamukhya and Ray [19] developed a decision support system employing AHP method to select the optimal cutting fluid having the minimum environmental impacts. Jagadish and Ray [20] adopted multiobjective optimization on the basis of simple ratio analysis (MOOSRA) method to select the finest cutting fluid that would minimize the environmental impact and cost and maximize surface quality. Kumar and Prasad [21] demonstrated the applicability of Chi-square statistic and matrix approaches for solving a cutting fluid selection problem in a given machining application. Chakraborty and Zavadskas [22] explored the applicability of weighted aggregated sum product assessment (WASPAS) method as an effective multicriteria decision making (MCDM) tool for cutting fluid selection. Tiwari and Sharma [23] employed simple additive weighting (SAW) and weighted product (WPM) techniques for choosing the best cutting fluid amongst different vegetable-based alternatives.

The review of the earlier research works reveals that a diverse range of MCDM methods and computer-based software has been applied for evaluation and selection of cutting fluids for varying machining applications. But, those previously implemented MCDM methodologies, such as AHP, TOPSIS, MOOSRA, SAW, WPM, digraph theory, and matrix approach, have some inherent limitations. For example, AHP method is generally complex and time consuming due to the formation of its pairwise comparison matrices. TOPSIS method captures only the objective criteria while ignoring the subjective ones, while MOOSRA method is quite sensitive to large variations in the rationalized values of the attributes. On the other hand, SAW method only employs maximizing evaluation criteria and therefore minimizing evaluation criteria should be converted into maximizing forms prior to their application. In digraph theory and matrix approach, the number of interrelationships between the considered evaluation criteria grows on considerably with increase in the number of attributes, and WPM method is designed to solve only those decision problems that involve criteria all of the same type. In addition, most of the past research works were focused on green manufacturing and 
considered only the occupational health and environmental hazards caused due to the applications of various cutting fluids in manufacturing industries. It is observed that till date no attempt has been made to include those factors that significantly affect the choice of cutting fluid, like (a) machining operation, (b) workpiece material, and (c) cutting material into the decision making framework. Moreover, the previously applied techniques did not provide any emphasis on the requirements of customers which play a crucial role in success and growth of any manufacturing industry. Therefore, there is an ardent need for establishment of a reliable and structured decision making model which can explicitly evaluate the quality and capability of cutting fluids to arrive at the best possible course of action. The QFD is a technique that can effectively incorporate customers' needs into a product. It also encourages group decision making where discussions continue until all the available and pertinent information are analyzed, and a consensus choice of alternatives most likely to attain the organization's stated goals is achieved. Thus, in this paper, a QFD-based model is developed in Visual BASIC 6.0 to choose the most suitable cutting fluid to achieve better process performance. The developed model would eliminate rigorous calculations and probable human error involved in the selection process through dramatically minimizing human intervention, thus reducing the time to arrive at the best cutting fluid selection decision.

\section{Development of a QFD-Based Model for Cutting Fluid Selection}

3.1. QFD Methodology. In the contemporary competitive environment, quality of product has been transformed into a hygiene factor instead of being a differentiating factor for the manufacturing organizations. Simultaneously, the emphasis of the organizations has been progressively focused on methods and techniques for supporting design and development of products which meet the specifications defined by the customers. Additionally, it is also eminent that consumers' wants and needs constantly vary with respect to time and are always dynamic in nature. Thus, the manufacturing organizations are required to implement a method which emphasizes on how to accommodate these changing needs into the designed product and even endeavor to forecast them in the near future that would benefit customers in long run. QFD is a method to capture each stated and unstated need of the customers within "voice of customers" and convert them into specific plans to manufacture products to meet those customers' requirements. It has the ability to evaluate performance of various technical requirements based on the needs of customers that can simplify, speed up, and improve the design cycle of the developed product. Unlike other approaches which focus more on engineering capabilities and less on customers' needs, QFD concentrates all product development activities on customers' needs.

QFD method employs a robust matrix, commonly known as house of quality (HOQ) matrix for documentation of the necessary information and perceptions about the product [24]. The HOQ matrix also depicts the relationships

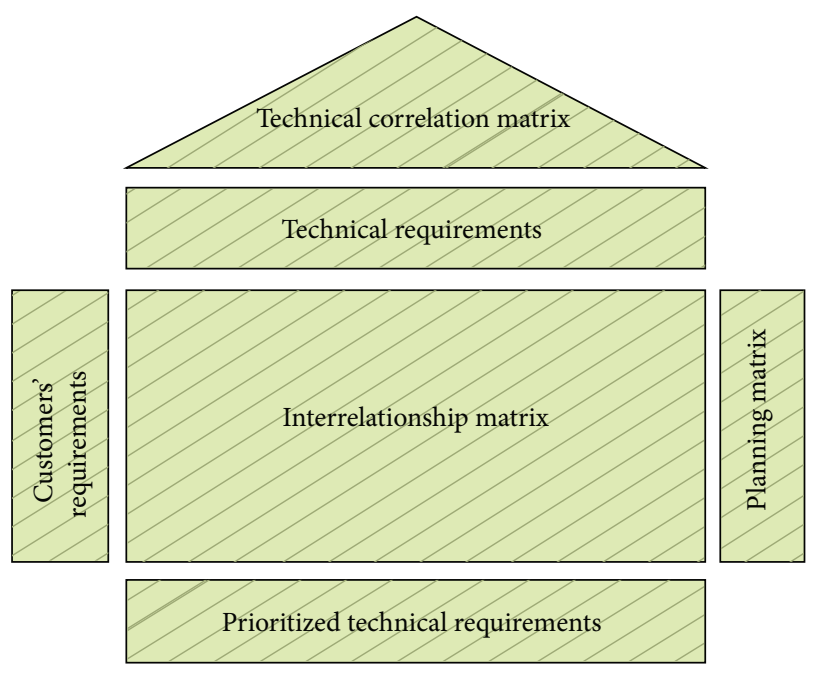

FIGURE 1: HOQ matrix.

between customers' needs and technical requirements of the considered product. Figure 1 exhibits the basic structure of a HOQ matrix with six major building blocks, that is, (a) customers' requirements: list of customers' wishes, expectations, and requirements from the product, (b) technical requirements: a set of technical descriptors that is to be considered with the intention to address the customers' needs, (c) interrelationship matrix: relationship between the customers' requirements and organization's ability to meet those requirements, marked using symbols or numbers, (d) technical correlation matrix: containing the correlation between the technical requirements, (e) planning matrix, describing quantified customers' requirements and ranking them in order of their importance, and (f) prioritized technical requirements: providing specific technical guidance about what needs to be preferred for quality product development. The importance of QFD methodology stems from the fact that both the customer and the organization are compelled to put effort to design the product in compliance with the instructions set down in the proffered $\mathrm{HOQ}$ matrix.

3.2. QFD-Based Model for Cutting Fluid Selection. Cutting fluids are extensively utilized in manufacturing industries to cater the varying needs of machining processes. Application of a cutting fluid has many benefits as discussed above; however, in certain instances, use of an inappropriate cutting fluid may hinder the material removal process instead of facilitating it. Thus, the process engineers need to have domain expertise and experience in order to analyze, evaluate, and choose the best cutting fluid alternative for a specific combination of machining operation, workpiece material, and cutting material. Additionally, cutting fluid selection is a process of addressing trade-offs between several competing demands of the customers, which involve huge time consuming computations. These issues can be tackled successfully through adoption of a QFD-based decision making model as it solves the cutting fluid selection problem while providing due importance to the needs of customers 


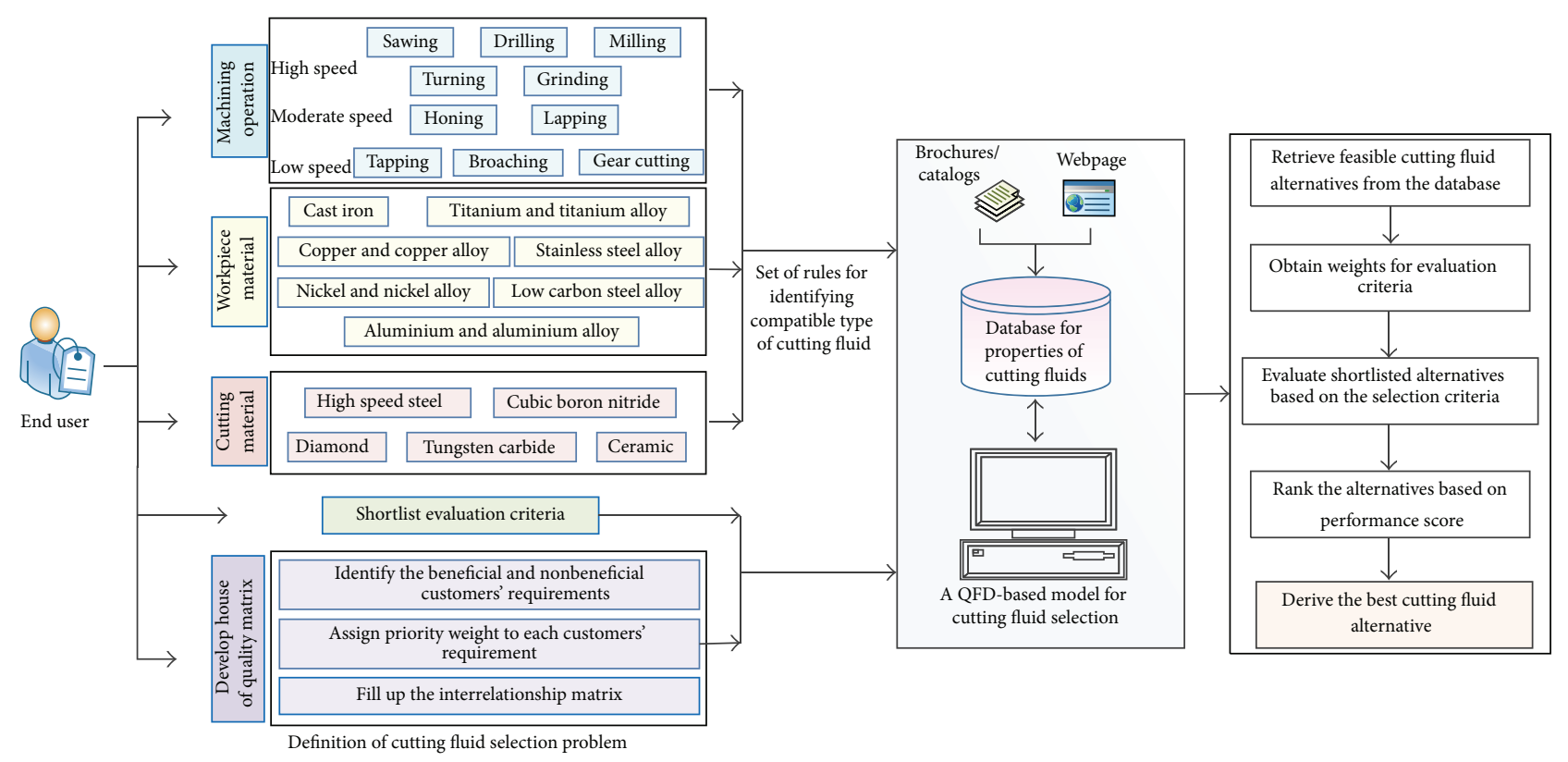

FIGURE 2: Architecture of the QFD-based model for cutting fluid selection.

(i.e., machining application requirements). This decision making framework is entirely automated through development of a software prototype which is integrated with a database of cutting fluids in order to minimize human intervention. The software prototype is designed in Visual BASIC 6.0 to have a user friendly graphical interface. Figure 2 depicts the architecture of the developed QFD-based model for cutting fluid selection. A detailed description involving the major steps in development of this QFD-based model is provided hereinunder.

In the first step, cutting fluids available in the market are categorized according to their composition and subsequently an exhaustive database of those cutting fluid types is developed. The pertinent information and detailed data regarding the properties of each category of cutting fluid are compiled from the catalogs and brochures of various cutting fluid manufacturers present on their corresponding websites.

Next, a critical analysis of the related past research works, published books, and periodicals $[11,25]$ is carried out to set rules to determine the compatibility of a specific cutting fluid for a particular combination of machining operation, workpiece material, and cutting material. These rules consequently govern the selection process of a cutting fluid. Turning, sawing, drilling, milling, grinding, honing/lapping, tapping, broaching, and gear cutting are the various machining operations, whereas cast iron, low carbon steel alloy, stainless steel alloy, copper and copper alloy, aluminium and aluminium alloy, nickel and nickel alloy, and titanium and titanium alloy are the different workpiece materials considered in this framework. On the other hand, cutting materials comprise high speed steel, tungsten carbide, cubic boron nitride, ceramic, and diamond.

Flow and pressure of a cutting fluid are determined by its mode of application, like flooding, spraying, dripping, misting, brushing, and so forth. Utilization of those cutting fluid application modes mainly depends upon the requirements of machining application and availability of the equipment. It is observed that a machine operator usually utilizes his knowledge and experience to opt for a particular mode of application of cutting fluid with a view to maximize its penetration to the point of contact considering all the facility constraints. Therefore, taking this into account, the developed QFD-based model is designed in such a way that the selection procedure of cutting fluid is not dependent on its flow and pressure. This facilitates flexibility in choosing the best cutting fluid based on all important criteria, and then according to availability of machineries and machining application requirements, one can vary pressure and flow of the selected cutting fluid while employing different modes of application.

After the choices related to the combination of the said three parameters are made, the first part of the third stage starts with the identification of various evaluation criteria from a detailed list of different physical and chemical properties associated with the cutting fluid. Density at $29^{\circ} \mathrm{C}$ (in $\mathrm{g} / \mathrm{cm}^{3}$ ), $\mathrm{pH}$ at $5 \%$ tap water, corrosion resistance (in relative (R) scale), flash point (in ${ }^{\circ} \mathrm{C}$ ), pour point (in ${ }^{\circ} \mathrm{C}$ ), viscosity at $40^{\circ} \mathrm{C}$ (in cSt), sulphur wt $\%$, chlorine wt $\%$, fatty ester wt $\%$, cost (in R scale), lubricity (in R scale), cooling (in R scale), foaming (in $\mathrm{R}$ scale), disposability (in $\mathrm{R}$ scale), recyclability (in $\mathrm{R}$ scale), and rancidity (in $\mathrm{R}$ scale) are taken into account as the most important properties for evaluating cutting fluids. Here, a relative scale of $1-5$ is used, where 1 and 5 represent the lowest and the highest values, respectively, as given in Table 1. These recognized evaluation criteria, also termed as technical requirements, are positioned at the top of HOQ matrix along its column.

A market survey is then conducted employing customers' feedback forms and questionnaires to accumulate demands of the customers related to selection of a cutting fluid. 
TABLE 1: Scale indicating relative values for cutting fluid properties.

\begin{tabular}{lc}
\hline Scale & Interpretation \\
\hline 1 & Lowest \\
2 & Low \\
3 & Moderate \\
4 & High \\
5 & Highest \\
\hline
\end{tabular}

TABLE 2: Scale indicating priority weight and correlation index.

\begin{tabular}{lcc}
\hline Scale & Priority weight & Correlation index \\
\hline 1 & Not important & Very, very weak relation \\
2 & Least important & Very weak relation \\
3 & Very less important & Weaker relation \\
4 & Less important & Weak relation \\
5 & Moderately important & Moderate relation \\
6 & Important & Strong relation \\
7 & Very important & Stronger relation \\
8 & Very, very important & Very strong relation \\
9 & Most important & Very, very strong relation \\
\hline
\end{tabular}

The important customers' requirements associated with selection of cutting fluid are identified as follows: the ability to dissipate the generated heat, to lubricate the contact surface, to wash away chips; protecting against corrosion, not foam or smoke away, having compatibility with the machine tool, facilitating good surface finish, being stable while in application and in storage, procurement cost, maintenance/recycling/disposal cost, deleterious effect on operator, nontoxic and odourless, noninflammable, and not causing pollution and bacterial contamination. These customers' requirements are placed along the rows of $\mathrm{HOQ}$ matrix.

The development of the related HOQ matrix is the final part of the third stage, which begins with identifying the beneficial or nonbeneficial customers' requirements. These customers' requirements are quantified by the value of the corresponding improvement driver $(+1$ for beneficial attribute and -1 for nonbeneficial attribute). A scale of 1-9, provided in Table 2, is set for assigning priority weights to the customers' requirements and highlighting the correlation between technical requirements and customers' requirements. A simplified HOQ matrix is adopted here which has only the prioritized technical requirements while not considering the technical correlation and planning matrices. After filling up the HOQ matrix with the necessary details, priority weights for the chosen criteria are derived on pressing "Weight" functional key. The weight for each evaluation criterion is computed using the following equation:

$$
w_{j}=\sum_{i=1}^{n} \operatorname{Pr}_{i} \times \mathrm{ID}_{i} \times \text { Correlation index }
$$

where $w_{j}$ is the weight for $j$ th technical requirement, $n$ is the number of customers' requirements, $\mathrm{ID}_{i}$ is the value of improvement driver for $i$ th customer requirement, $\operatorname{Pr}_{i}$ is the priority assigned to $i$ th customer requirement, and correlation index is the relative importance of $j$ th technical requirement with respect to $i$ th customer requirement.

The last stage of this model embarks with establishing the decision matrix to obtain performance scores for the shortlisted cutting fluid alternatives. The developed framework provides the end user with two options, that is, "cutting fluid alternatives from database," that is, to choose suitable cutting fluid alternatives from the integrated database and "customized cutting fluid alternatives," that is, flexibility to fill up the decision matrix with relevant details of the suitable cutting fluid options according to the end user's choice. Once the decision matrix is completely developed, a linear normalization approach is employed to generate a normalized matrix to make it dimensionless and comparable. Now, the performance score for each cutting fluid alternative is calculated using the following expression:

$$
\begin{aligned}
& \text { Performance score }\left(\mathrm{PS}_{i}\right) \\
& =\sum_{j=1}^{n} w_{j} \times(\text { Normalized value })_{i j} \\
& \qquad(i=1,2, \ldots, m ; j=1,2, \ldots, n),
\end{aligned}
$$

where $w_{j}$ is the weight for $j$ th technical requirement, $m$ is the number of alternatives, and $n$ is the number of technical requirements. The weights for the technical requirements are automatically retrieved from the HOQ matrix. Based on these performance scores, the shortlisted cutting fluid alternatives are ranked and the most appropriate one for the given machining application is thus identified. The performance score of each cutting fluid alternative is also displayed pictorially.

\section{Illustrative Examples}

Two illustrative examples are demonstrated and subsequently solved in this paper to validate the potentiality and applicability of the developed QFD-based model for cutting fluid selection.

4.1. Illustrative Example 1. In this example, the most suitable cutting fluid is intended to be selected for drilling holes in titanium alloy employing drill bits of tungsten carbide. The selection procedure begins with choosing the relevant details about the machining operation, workpiece material, and cutting material from various options available in the opening window of the developed framework, as shown in Figure 3. It is well acknowledged that drilling is a high speed machining operation where moderate cutting pressure is applied. Moreover, the geometry of the formed chips hinders the cutting fluid to reach the workpiece surface. These factors result in appreciable rise in temperature at the machining surface that deters the performance of the said operation. Therefore, cooling action of the cutting fluid is more essential than its lubricating effect in drilling. Titanium alloys are difficult-to-cut materials and owing to this, more heat is generated during their machining operation. Thus, the application of cutting fluid should minimize the effect of 


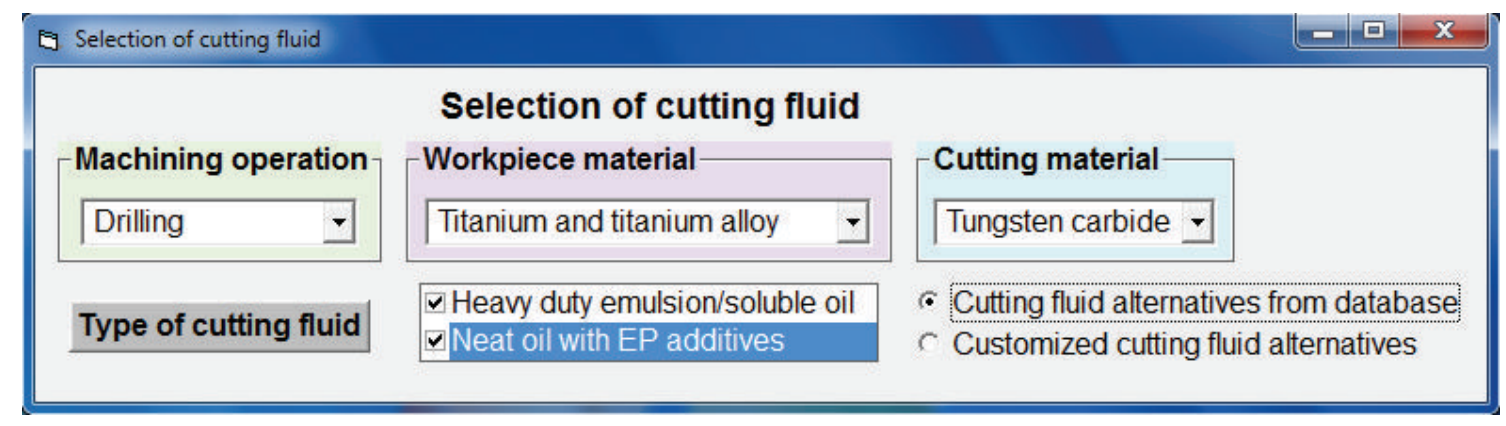

FIgURE 3: Opening window for Example 1.

the generated heat. Additionally, when tungsten carbide tool is used, there is a significant temperature rise at the interface of cutting tool and workpiece material. Occasionally, this may result in welding between the chip and the tool which in turn causes rapid tool wear. In order to avoid this problem, the selected cutting fluid must have both cooling and lubricating properties. The governing rules of the developed framework assist in identifying "heavy duty emulsion/soluble oil" and "neat oil with extreme pressure (EP) additives" as the potential candidates of cutting fluid in this case. Both these categories of cutting fluids are considered here for subsequent evaluation. Here, "cutting fluid alternatives from database" option is chosen in order to retrieve the feasible cutting fluid alternatives from the integrated database of the developed model.

In the subsequent stage of this selection procedure, different important evaluation criteria which affect the cutting fluid selection process are identified as density, flash point, fatty ester wt $\%$, cost, and rancidity. The "HOQ matrix" functional key is then pressed to generate an empty HOQ matrix. The improvement driver values articulating beneficial and nonbeneficial attributes of the customers' requirements are then filled up in the HOQ matrix. The priority values for the considered customer's requirements are also entered into their respective positions. The correlation indices indicating the interrelationships between customers' requirements and technical requirements are then put into the HOQ matrix. Once all the relevant data are assigned to HOQ matrix, "Weight" functional key is pressed to derive the priority weight for each of the considered evaluation criteria. It is observed that density, rancidity, and cost have negative priority weights as they are the nonbeneficial attributes, whereas flash point and fatty ester wt $\%$ with positive priority weights are always preferred with their higher values. A set of seven alternatives to be evaluated is chosen from the list of feasible cutting fluids for final selection of the most appropriate option, as exhibited in Figure 4. The filledup HOQ matrix can be again made blank or refreshed on pressing of "Clear" functional key.

The final decision matrix for this cutting fluid selection problem is developed in another window from the database on pressing "decision matrix" functional key. The performance scores and ranking preorder of the finally shortlisted seven cutting fluid alternatives along with a graphical representation of their performance scores are shown in Figure 5. This QFD-based model identifies HD CUTSOL as the most suitable cutting fluid for drilling holes in titanium and its alloy, followed by UNICUT 5. This is revealed from the specifications of HD CUTSOL that it can successfully satisfy all the identified evaluation criteria. Cost, flash point, and rancidity are the three criteria having considerable impact on the selection of the potential cutting fluid due to their higher priority weights. HD CUTSOL has the lowest cost and rancidity values among all the seven alternatives, although its flash point is moderately high. These factors suitably justify the selection of HD CUTSOL as the best cutting fluid for the considered machining operation.

4.2. Illustrative Example 2. This example illustrates the selection procedure of the most suitable cutting fluid for performing honing operation on stainless steel alloy with cubic boron nitride tool. Thus, "honing/lapping," "stainless steel alloy," and "cubic boron nitride" are, respectively, chosen as the machining operation, workpiece material, and cutting material, as exhibited in Figure 6. "Type of cutting fluid" key is then pressed to identify "honing fluid" as the compatible category of cutting fluid for the above-mentioned combination. Here, "customized cutting fluid alternatives" option is chosen so that the end user has the flexibility to evaluate honing fluid alternatives that are not present in the database. The end user needs to provide the detailed physical property values of the new cutting fluids as the developed model has not the scope of retrieving the relevant information from its database.

For this selection problem, corrosion resistance, viscosity, sulphur wt\%, and recyclability are considered as the most significant evaluation criteria based on their effects on the machining requirements. The developed model then generates an empty HOQ matrix which is subsequently filled up by the end user with pertinent details. The corresponding HOQ matrix is exhibited in Figure 7 where the priority weights for different evaluation criteria of this honing fluid selection problem are shown as already computed. A negative priority weight of viscosity indicates that its lower value is always preferred, whereas, for the other three criteria, that is, corrosion resistance, sulphur wt $\%$, and recyclability, it is always better to have their higher values. Next, the number of 


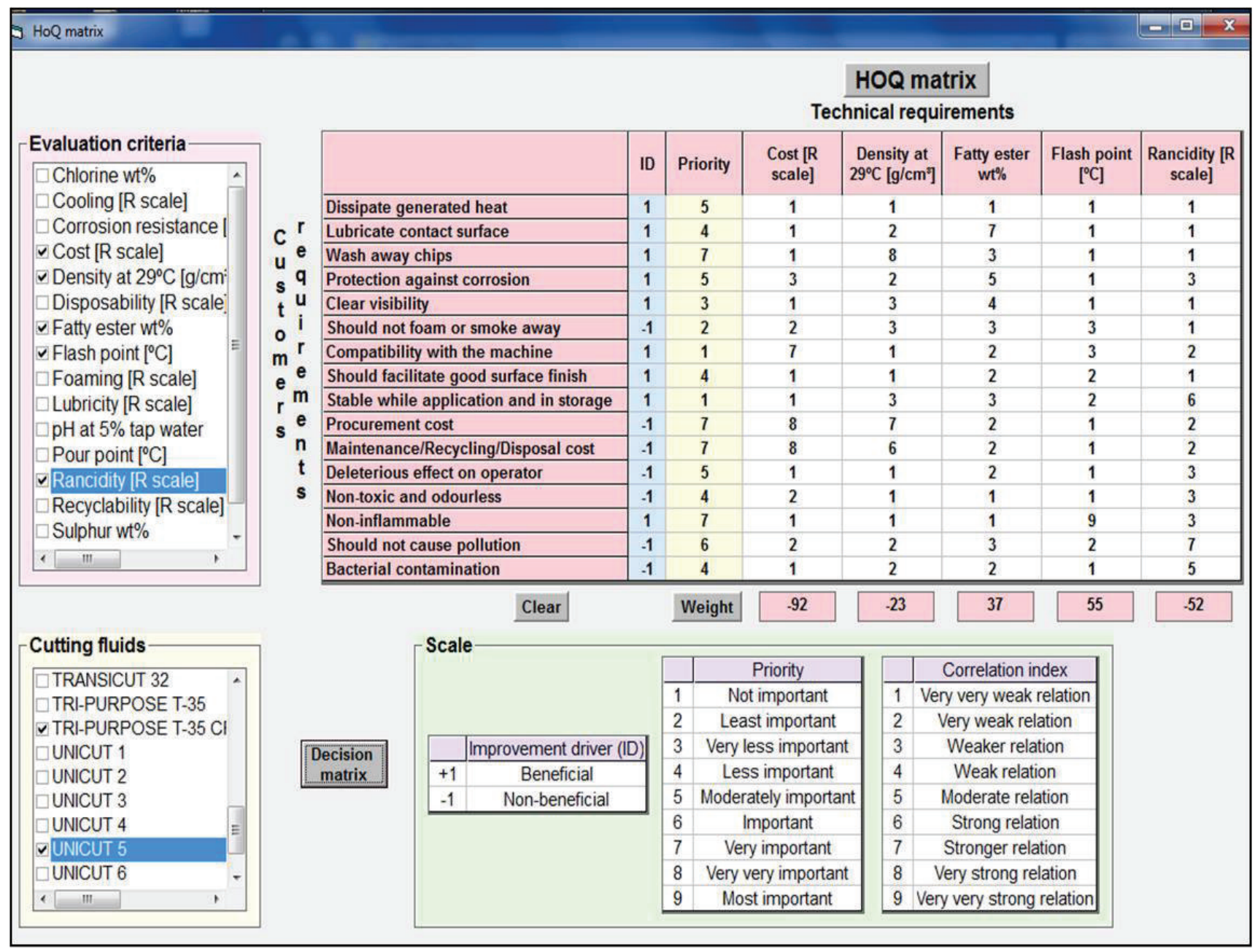

FIgURE 4: HOQ matrix for Example 1.

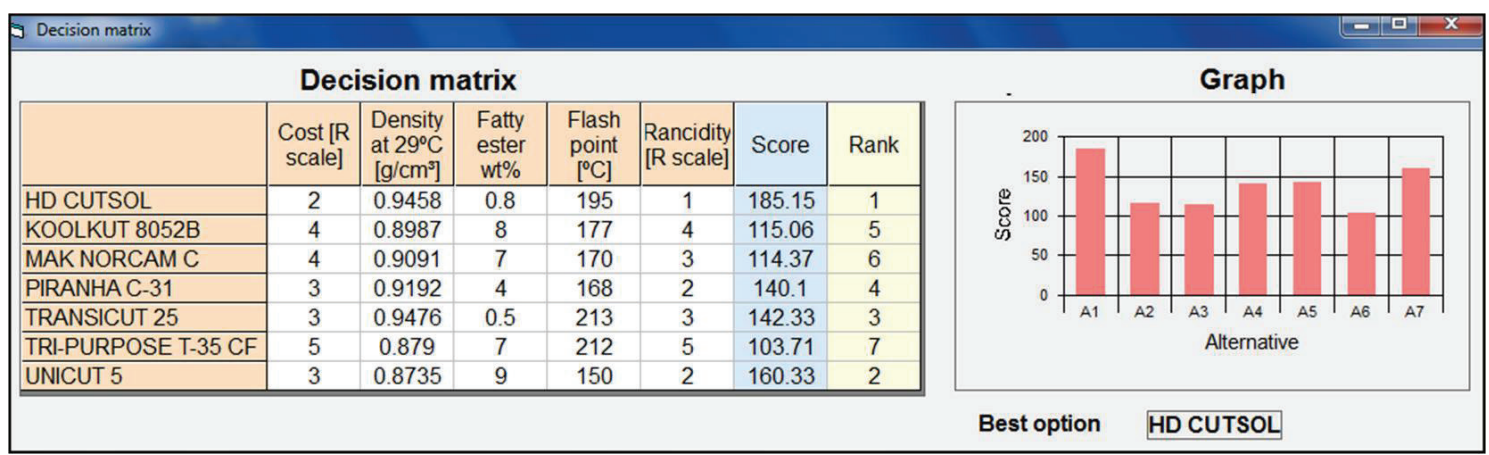

FIgURE 5: Decision matrix for Example 1.

alternatives to be examined is entered and "decision matrix" functional key is pressed to generate a blank decision matrix for evaluation of honing fluids.

Now, the end user provides all the necessary data for the five honing fluid alternatives as required for calculating their performance scores in the decision matrix, as shown in Figure 8. On pressing "Score" functional key, the performance scores of all the considered honing fluids, their rankings, and a visual display of the relative positions of the alternative honing fluids are obtained. Here, CF5 emerges out as the most suitable honing fluid. Corrosion resistance has the maximum priority weight in this case, followed by recyclability. On the other hand, this selection process is least affected by viscosity of the honing fluid. A closer review of all 


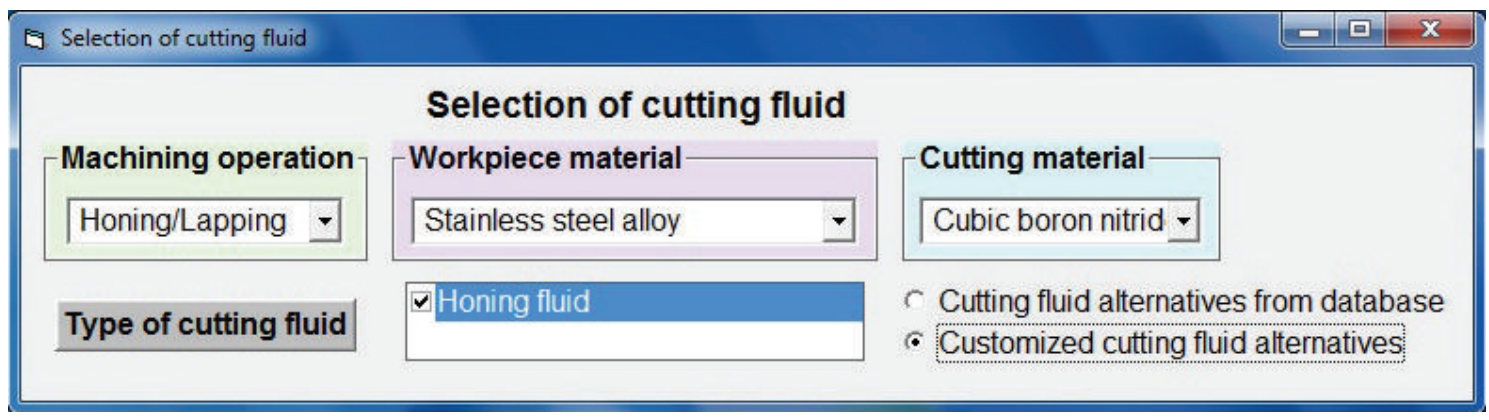

Figure 6: Opening window for Example 2.

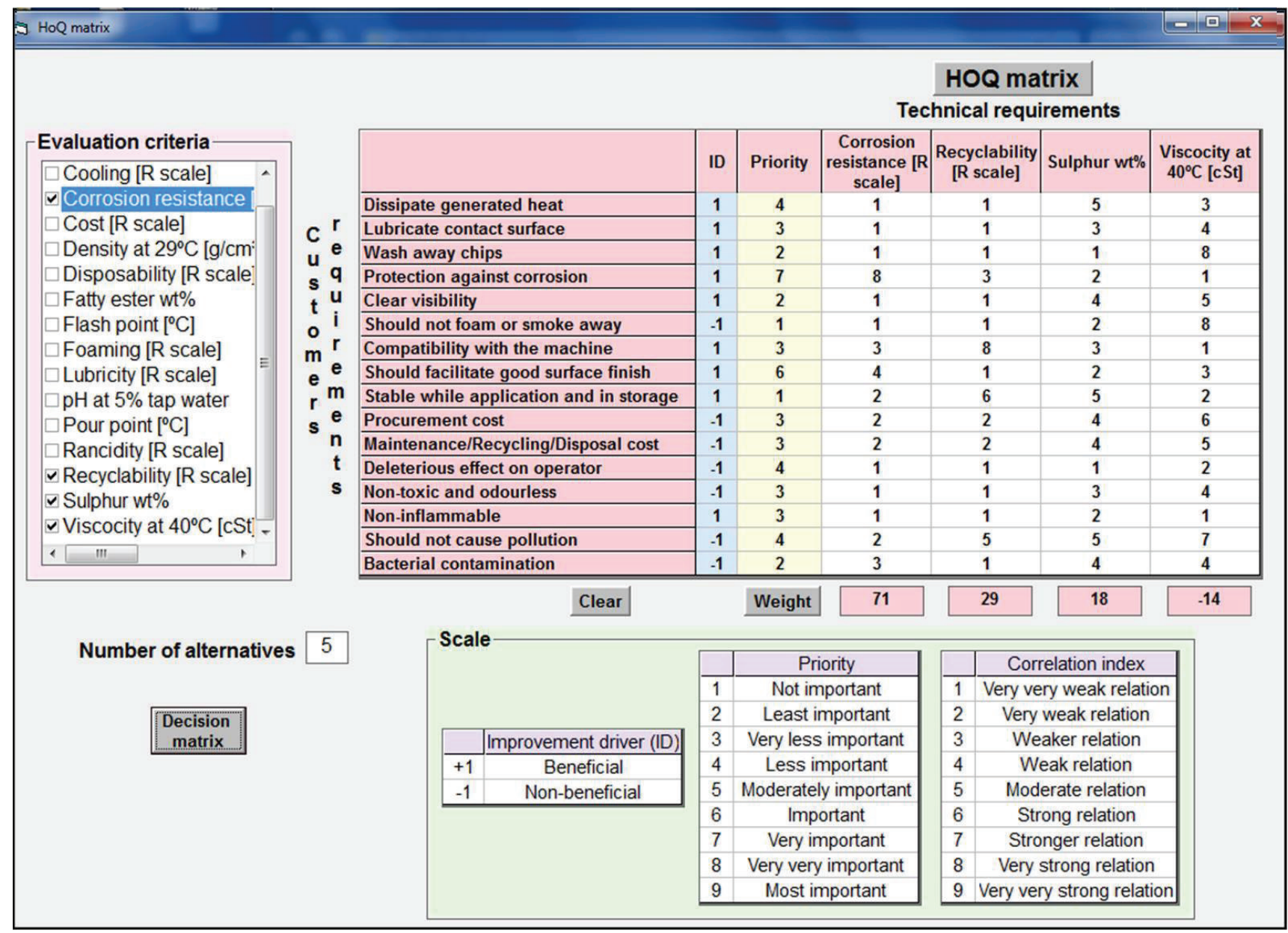

FIGURE 7: HOQ matrix for Example 2.

the properties of CF5 divulges that it has the highest value for corrosion resistance. Recyclability value for CF5 is also comparatively high. Hence, it can be comprehended that the result derived from the application of QFD-based model; that is, CF5, as the most suitable honing fluid, is truly justified.

\section{Conclusions}

In the current scenario of rapid technological advancement, cut-throat competition, and information processing revolution, manufacturing organizations are being compelled to relentlessly develop innovative methods/technologies to produce high quality products/components at the lowest possible cost and time to cater the diverse and dynamic needs of customers. Thus, this paper emphasizes on development of a QFD-based model to automate the entire decision making process for selecting the best cutting fluid alternative for a given machining condition. The graphical user interface built in Visual BASIC 6.0 facilitates a seamless interaction of the developed model with the process engineers. The level 


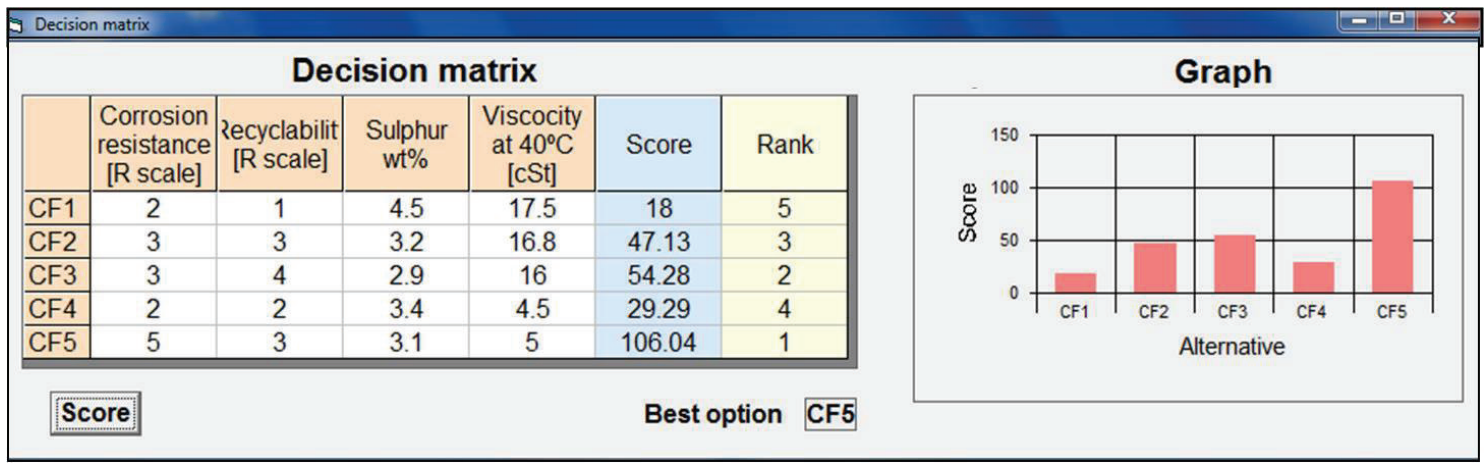

Figure 8: Decision matrix for Example 2.

of human intervention is drastically reduced, requiring no in-depth technical knowledge regarding the cutting fluid's applicability, capability and economy, and related effects of the considered evaluation criteria on the machining operation. It implies that the developed QFD-based decision making model minimizes human error, thereby assisting in better management of cutting fluids through ascertaining an effective and productive work culture in the organization. The approach of continuous improvement of the manufacturing organization is also supported through periodic upgrading of the database with the changing business environment. Moreover, this designed framework is flexible in nature in two dimensions. At first, it includes a wide range of cutting fluid alternatives from diverse manufacturers into its database, and secondly the end user is provided with two options, that is, evaluating the common cutting fluids retrieved from the existing database or examining special ones through personally entering their details. The results derived from implementation of this QFD-based model exactly corroborate with the practiced choices of the industrial experts. The application of this model also reduces manpower requirement, enhances personnel efficiency, and utilizes information effectively, thus minimizing the overall machining cost.

\section{Conflict of Interests}

The authors declare that there is no conflict of interests regarding the publication of this paper.

\section{References}

[1] L. De Chiffre and W. Belluco, "Comparison of methods for cutting fluid performance testing," Annals of the CIRP, vol. 49, no. 1, pp. 57-60, 2000.

[2] R. F. Ávila and A. M. Abrão, "The effect of cutting fluids on the machining of hardened AISI 4340 steel," Journal of Materials Processing Technology, vol. 119, no. 1-3, pp. 21-26, 2001.

[3] D. A. Axinte, W. Belluco, and L. De Chiffre, "Reliable tool life measurements in turning-an application to cutting fluid efficiency evaluation," International Journal of Machine Tools and Manufacture, vol. 41, no. 7, pp. 1003-1014, 2001.

[4] R. V. Rao and O. P. Gandhi, "Digraph and matrix method for the selection, identification and comparison of metal-cutting fluids," Proceedings of the Institution of Mechanical Engineers Part J, vol. 215, no. 1, pp. 25-33, 2001.

[5] W. F. Sales, A. E. Diniz, and A. R. Machado, "Application of cutting fluids in machining processes," Journal of the Brazilian Society of Mechanical Sciences, vol. 23, no. 2, pp. 227-240, 2001.

[6] M. Soković and K. Mijanović, "Ecological aspects of the cutting fluids and its influence on quantifiable parameters of the cutting processes," Journal of Materials Processing Technology, vol. 109, no. 1-2, pp. 181-189, 2001.

[7] J. Sun, P. Ge, and Z. Liu, “Two-grade fuzzy synthetic decisionmaking system with use of an analytic hierarchy process for performance evaluation of grinding fluids," Tribology International, vol. 34, no. 10, pp. 683-688, 2001.

[8] L. De Chiffre and W. Belluco, "Investigations of cutting fluid performance using different machining operations," Lubrication Engineering, vol. 58, no. 10, pp. 22-29, 2002.

[9] X. C. Tan, F. Liu, H. J. Cao, and H. Zhang, "A decisionmaking framework model of cutting fluid selection for green manufacturing and a case study," Journal of Materials Processing Technology, vol. 129, no. 1-3, pp. 467-470, 2002.

[10] A. S. Varadarajan, P. K. Philip, and B. Ramamoorthy, "Investigations on hard turning with minimal cutting fluid application (HTMF) and its comparison with dry and wet turning," International Journal of Machine Tools and Manufacture, vol. 42, no. 2, pp. 193-200, 2002.

[11] O. Cakir, A. Yardimeden, T. Ozben, and E. Kilickap, "Selection of cutting fluids in machining processes," Journal of Achievements in Materials and Manufacturing Engineering, vol. 25, no. 2, pp. 99-102, 2007.

[12] N. D. Rao, R. R. Srikant, and C. S. Rao, "Influence of emulsifier content on properties and durability of cutting fluids," Journal of the Brazilian Society of Mechanical Science and Engineering, vol. 24, no. 4, pp. 396-400, 2007.

[13] A. D. Jayal and A. K. Balaji, "Effects of cutting fluid application on tool wear in machining: interactions with tool-coatings and tool surface features," Wear, vol. 267, no. 9-10, pp. 1723-1730, 2009.

[14] R. V. Rao and B. K. Patel, "Decision making in the manufacturing environment using an improved PROMETHEE method," International Journal of Production Research, vol. 48, no. 16, pp. 4665-4682, 2010.

[15] D. Fratila and C. Caizar, "Application of Taguchi method to selection of optimal lubrication and cutting conditions in face milling of $\mathrm{AlMg}_{3}$," Journal of Cleaner Production, vol. 19, no. 6-7, pp. 640-645, 2011. 
[16] J. Meciarova and M. Stanovsky, "Cutting fluids evaluation based on occupational health and environmental hazards," Engineering for Rural Development, vol. 10, pp. 418-422, 2011.

[17] L. Abhang and M. Hameedullah, "Selection of lubricant using combined multiple attribute decision-making method," Advances in Production Engineering \& Management, vol. 7, no. 1, pp. 39-50, 2012.

[18] Jagadish and A. Ray, "Cutting fluid selection for sustainable design for manufacturing: an integrated theory," Procedia Materials Science, vol. 6, pp. 450-459, 2014.

[19] T. Deshamukhya and A. Ray, "Selection of cutting fluid for green manufacturing using analytical hierarchy process (AHP): a case study," International Journal of Mechanical Engineering and Robotics Research, vol. 3, no. 1, pp. 173-182, 2014.

[20] Jagadish and A. Ray, "Green cutting fluid selection using MOOSRA method," International Journal of Research in Engineering and Technology, vol. 3, no. 15, pp. 559-563, 2014.

[21] E. S. R. R. Kumar and J. S. R. Prasad, "A novel approach of obtaining theoritical values in selection of cutting fluid attributes," IOSR Journal of Mathematics, vol. 10, no. 5, pp. 1-4, 2014.

[22] S. Chakraborty and E. K. Zavadskas, "Applications of WASPAS method in manufacturing decision making," Informatica, vol. 25, no. 1, pp. 1-20, 2014.

[23] V. V. Tiwari and A. Sharma, "MADM for selection of vegetable based cutting fluids by SAW method and WPM method," International Journal of Research in Technology and Management, vol. 1, no. 1, pp. 16-27, 2015.

[24] K. Prasad, E. K. Zavadskas, and S. Chakraborty, "A software prototype for material handling equipment selection for construction sites," Automation in Construction, vol. 57, pp. 120-131, 2015.

[25] Production Technology-HMT Bangalore, Tata McGraw-Hill Publishing Company Limited, New Delhi, India, 1980. 


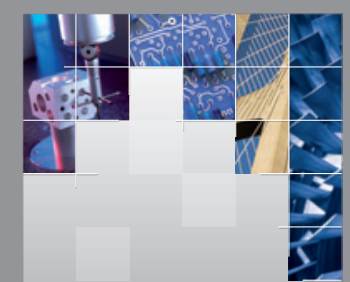

\section{Enfincering}
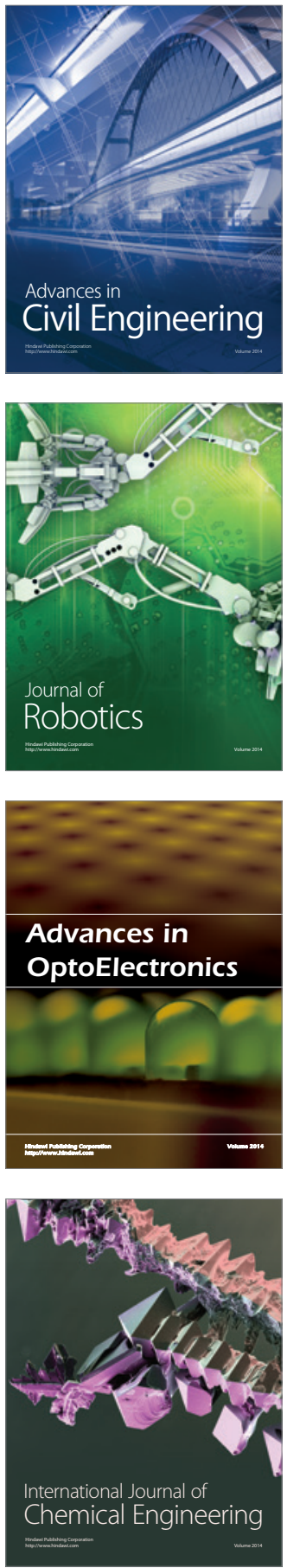

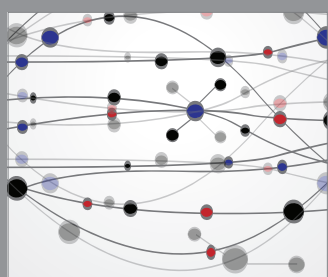

The Scientific World Journal

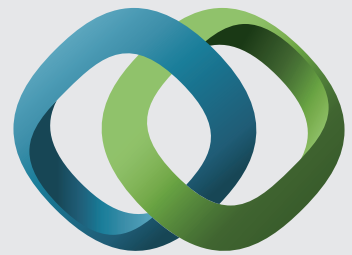

\section{Hindawi}

Submit your manuscripts at

http://www.hindawi.com
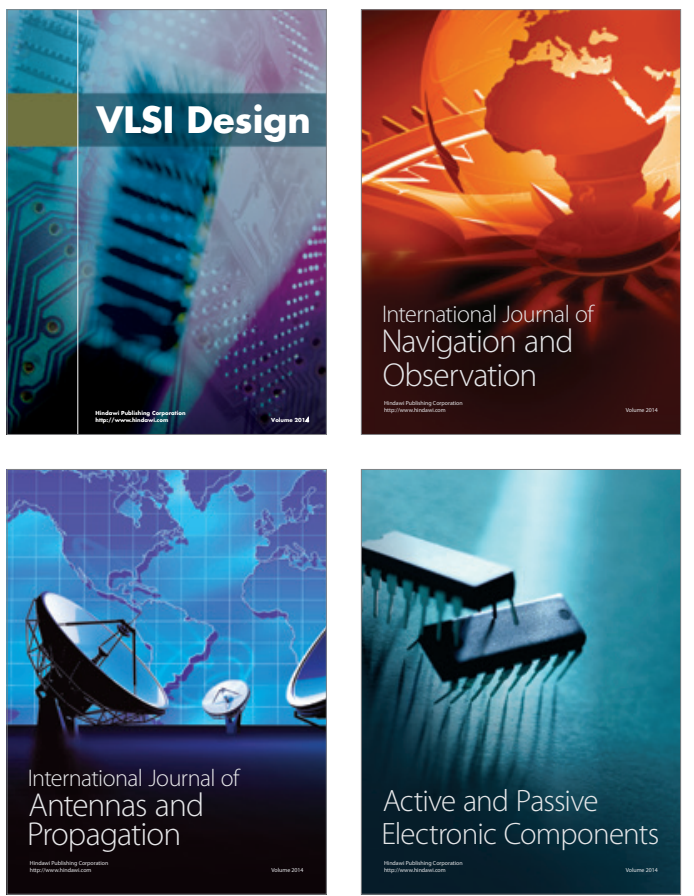
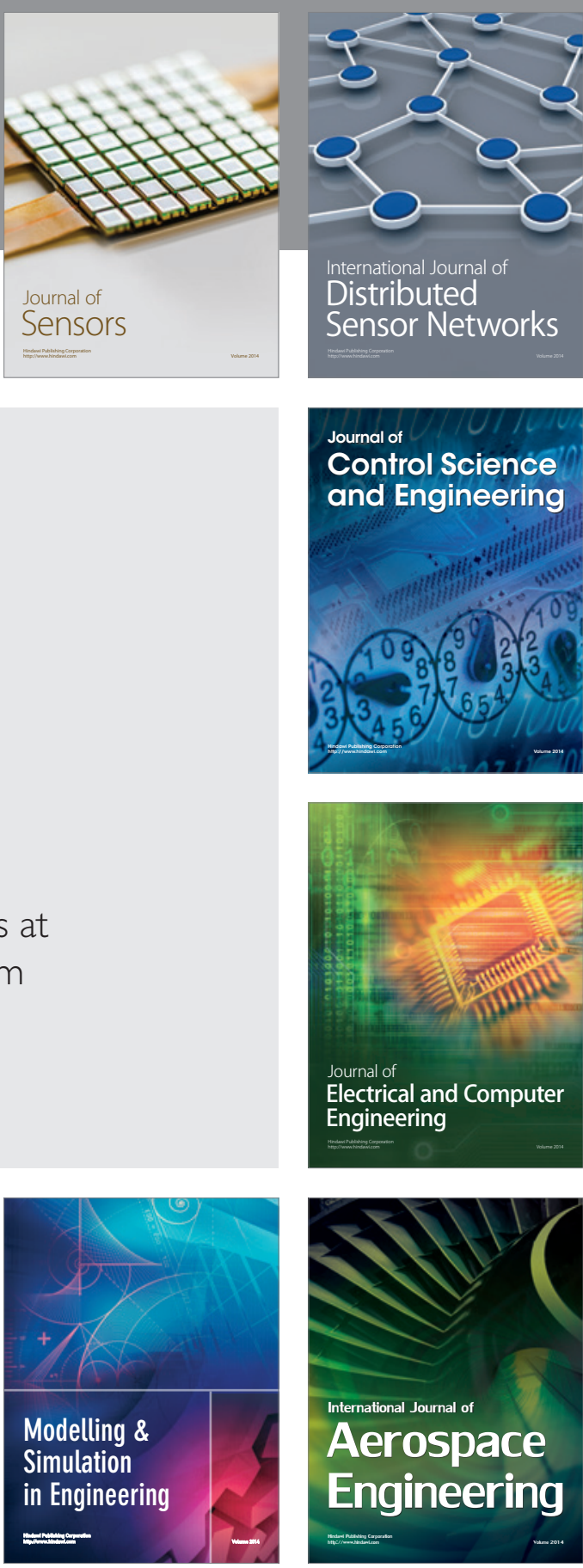

International Journal of

Distributed

Sensor Networks

Journal of

Control Science

and Engineering
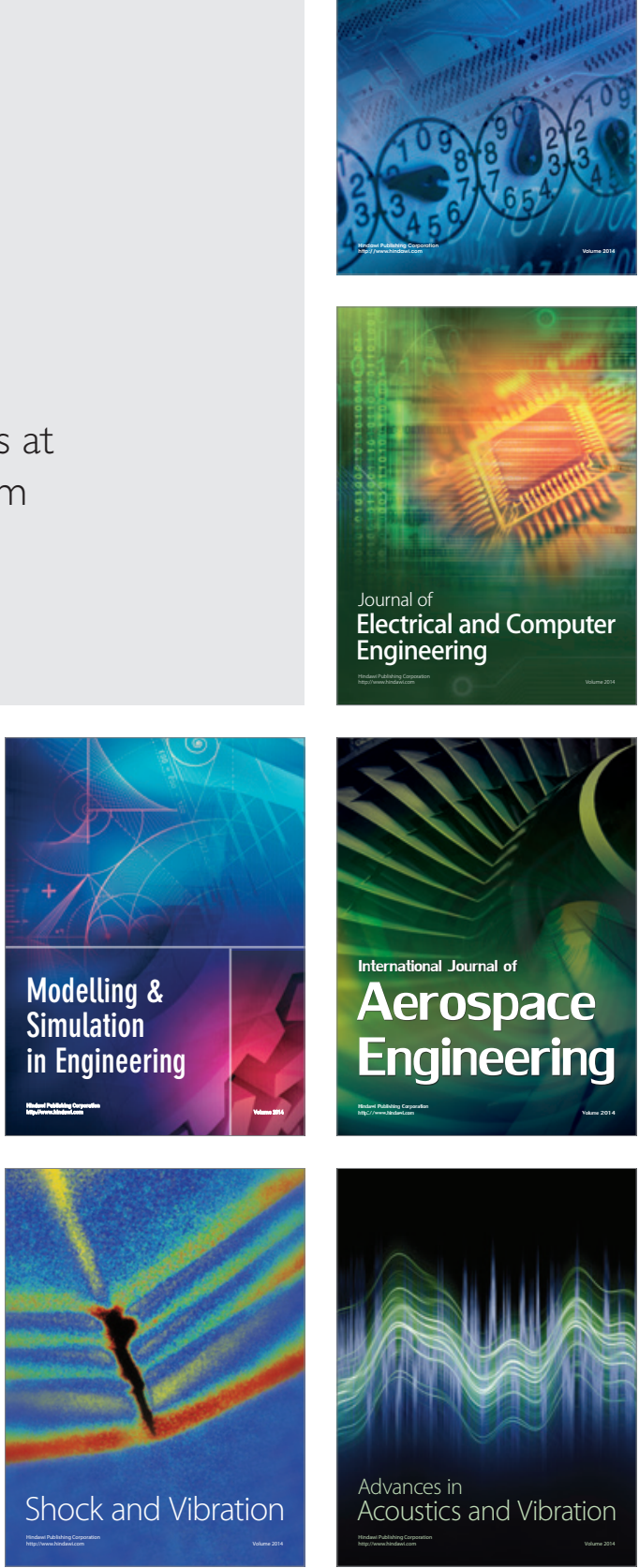